Revista do Programa de Pós-Graduação em Mídia e Cotidiano

Artigo Seção Dossiê Mídia e Cidade

Número 6. Volume 6 /Julho 2015

(C) 2015 by UFF

\title{
AS CIDADES E SUAS LINGUAGENS CONTRA O LEVIATÃ
}

\section{CITIES AND LANGUAGES AGAINST LEVIATHAN}

\author{
Wellington PEREIRA ${ }^{1}$ e Nayanne NÓBREGA ${ }^{2}$
}

Resumo: Este ensaio busca compreender como o jornalismo impresso enuncia as manifestações de junho de 2013 através dos discursos verbais e imagéticos; verificando se o caráter polissêmico das imagens foi respeitado pela lógica da nomeação jornalística. Durante esses protestos, observamos que as novas linguagens, objetivas ou subjetivas, foram eficazes na luta contra o poder do Leviatã. Ao mesmo tempo em que nos deparamos com a ampliação de fronteiras e a elasticidade das cidades pósmodernas. Diante disso, o que significa as imagens de pessoas pedindo a volta da Ditadura Militar pelas ruas das maiores cidades do País?

Palavras-chave: Jornalismo; Discurso; Cidades; Protestos; Leviatã;

Abstract: This essay pretends to understand how print journalism lists the manifestations of June 2013 through verbal imagery and speeches; verifying that the ambiguous character of the images was respected by the logic of journalistic appointment. During these protests, we see that the new languages, objective or subjective, were effective in the fight against the power of Leviathan, while we face the expansion of borders and the elasticity of postmodern cities. In view of this, what means the images of people asking for the return of the military dictatorship through the streets of the largest cities in the country?

Keywords: Journalism; Speech; Cities; Protests; Leviathan;

\footnotetext{
1 Doutor em Sociologia pela Université Paris V -Sorbonne - Professor da Pós-Graduação em Comunicação (PPGC) da Universidade Federal da Paraíba (UFPB) e do curso de Mídias Digitais. Coordena, desde 2002, o Grupecj- Grupo de Pesquisa sobre o Cotidiano e o Jornalismo E-mail: wjdop@uol.com.br

2 Mestranda no Programa de Pós-Graduação em Comunicação (PPGC), linha de pesquisa Mídia, Cotidiano e Imaginário, pela Universidade Federal da Paraíba (UFPB) e graduada em Comunicação Social/Habilitação Jornalismo pela mesma instituição. Atualmente pesquisa a construção do discurso analógico enunciado pelos jornais paraibanos sobre as manifestações de junho de 2013. Possui experiência como jornalista, nas áreas de assessoria de comunicação e jornalismo impresso. E-mail: nayannenobrega@gmail.com
} 


\section{INTRODUÇÃO}

As manifestações ocorridas em junho de 2013 foram consideradas pela imprensa um dos maiores acontecimentos políticos dos últimos anos. O movimento conseguiu juntar milhões de pessoas nas vias públicas das principais cidades do Brasil. Mas o que significa as imagens de pessoas pedindo a volta da Ditadura Militar pelas ruas das maiores cidades do País?

Em primeiro lugar, o ser humano, se interrogado forçosamente, dificilmente assume que deseja reviver atos de tortura ou barbárie. Em segundo lugar, o significado da palavra Ditadura é extensivo ao recrudescimento de quaisquer liberdades individuais, o que todo cidadão - de qualquer matiz ideológico-abomina.

Por que pedir a volta de um regime político que assassina a ontologia (o estado do ser)? Um dos caminhos comuns para o entendimento dessas ações está na palavra medo. Mas medo de que, de quem? Medo que o homem tem do Homem. Mas esta não é uma explicação isolada.

O medo pode se tornar uma prática coletiva, se considerarmos três aspectos: 1) no estado de natureza os homens se sentem iguais para xingar e serem xingados; 2) vivem em um estado de desconfiança total; 3) alimentam, nas convivências (digitais ou não) um medo recíproco. Mas para ultrapassar esses três elementos, os homens usam o medo como medium e abdicam de seus direitos através de um contrato "social" outorgado por sistemas de proteção: tecnologias, religiões, partidos políticos.

Carlo Ginzburg, em seu livro, Medo, reverência, terror - quatro ensaios de iconografia política, traz ao centro da discussão o filósofo inglês Hobbes e sua iconografia do medo representada pelo Leviatã. Hobbes diz que todo pacto é válido, 'mesmo que seja estipulado numa situação de medo'. Ora, pedir a intervenção de uma força destruidora das garantias individuais, como a ditadura, é um ato de medo. Esse medo que pede o retorno da Ditadura Militar se traduz no medo das perdas "garantidas" por uma sociedade cuja extensão é o sistema escravocrata e o latifundiário. Em suma, medo de perder a posse da jus naturalização do corpo da mulher "amada", da fala das crianças, da moral imputada às minorias sociais. Como diz Hobbes, (apud Ginzburg) o 


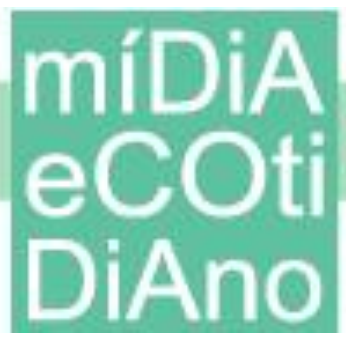

medo gera impulsos para sair do medo. Esses impulsos descaracterizam a polis (o espaço natural da cidadania) e reforçam a sociedade do medo.

Assim, as iconografias da nossa política contemporânea reforçam o medo dos feios, dos mais pobres, daquela gente de pele escura que se aproxima, cada vez mais, do centro das cidades. E matamos nossos protestos juvenis - sem perceber a espessura do tempo histórico. Ao invés de "Ditadura Nunca Mais", recrudescemos ao Ditadura, já!

\section{1- O enfretamento do Leviatã nos labirintos das cidades.}

Nos labirintos das cidades pós-modernas se enfrenta o Leviatã ou se pede a sua proteção com medo do Estrangeiro - na verdade do outro - que aparece muito próximo de nossas fronteiras. Como nos demonstra Bauman: “...Trata-se do seguinte: quanto mais o espaço e a distância se reduzem, maior é a importância que sua gente lhe atribui, quanto mais é depreciado o espaço, menos protetora é a distância, e mais obsessivamente as pessoas traçam e deslocam fronteiras (...)" (Bauman, 2009, ebook posição $74 \%$ ).

$\mathrm{Na}$ verdade, o deslocamento das fronteiras tem se dado em função da velocidade e da difusão imaterial que as novas mídias têm outorgado à sociação entre os atores sociais nos espaços urbanos: "É, sobretudo nas cidades, que se observa essa furiosa atividade de traçar e deslocar fronteiras entre as pessoas" (Bauman, 2009, ebook posição $74 \%)$.

A ampliação de fronteiras entre pessoas nas cidades brasileiras foi sentida de forma aguda nas manifestações de junho de 2013, quando problemas locais se transformaram em problemas nacionais, conjugando políticas a partir de problemas globais. As fronteiras passaram a ser demarcadas para demonstrar as particularidades, sobretudo no uso das linguagens, de cada grupo social.

$\mathrm{Na}$ verdade, essas fronteiras linguageiras vão ampliando a semântica das ações da força centrípeta à força centrífuga - que, por sua vez teme se deslocar para o eixo de oposição e perder sua força. Isso pode caracterizar o medo do Estado das manifestações de rua, porque elas colocam em risco o contrato com o Leviatã. 
O problema é que o Leviatã começa a ser profanizado a partir do uso das linguagens dos diversos grupos das cidades que provocam uma bolha social na qual ora o Estado aparece no centro, ora à margem.

Nesse sentido, as divisões de classe (no sentido marxista) ou a divisão social do trabalho (à la Durkheim) se confundem com um éthos que nada mais é que o logos da cultura local, aquilo que interfere de forma hodierna nas configurações do mundo da vida.

O que o estado, na maioria das vezes, não entende é que o contrato de confiança não está mais sob os auspícios do Leviatã. Confiança e Medo são construídos no hic et nunc (no aqui e agora) e depende da associação entre as novas tecnologias e o pathos (as formas de agrupamento social) das comunidades consideradas "supérfluas" pela modernização.

Surge, assim, a construção de uma nova ordem social nas cidades que não se caracteriza apenas como o "grito dos explorados", mas como a soma desse grito a outros gritos que trafegam do centrípeto ao centrífugo e vice-versa. Isso quer dizer: o tecido social está mais frouxo, com nódoas visíveis e perdas constantes das formas verticalizadas.

O poder teme a mobilidade das ruas, porque não se preparou - na tradição das Repúblicas ocidentais - para ser móvel. Isso permite a investigação de como a geometria das cidades vão modificando a rigidez da sociedade.

\section{2- As geometrias das cidades simmelianas contra o medo cotidiano}

Ao enfrentar os petardos geométricas atirados pelas linguagens da cidade, o Leviatã se enfraquece diante das exigências de uma nova ordem social. Assim, a cidade seria uma ação-tipo, sempre em movimento capaz de unir o nobre, o estrangeiro e os pobres numa relação espaço-temporal infinitos.

Somos formas sociais que não se deixam apreender pelo léxico jurídico do Estado ou mesmo pelos conceitos sociológicos. Até mesmo os tipos ideias weberianos 


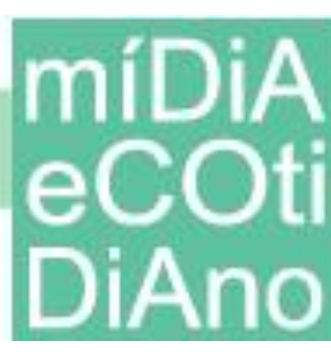

não dão conta das projeções dos perfis das lideranças a partir de uma visão macropolítica.

O que os movimentos de rua têm demonstrado é que precisamos entender como nos ensina Georg Simmel que há uma elasticidade das formas sociais diretamente relacionadas às novas formas estéticas criadas e recriadas pelo pathos dos manifestantes.

Um dos conflitos estabelecidos por estas novas formas linguageiras das manifestações de rua se deu com a modificação abrupta dos padrões jornalísticos: o uso das novas tecnologias que privilegiam a velocidade na difusão das notícias à gramaticalidade do jornalismo, ou seja, a informação não depende mais de cancelas.

Novamente, com a imbricação entre o pathos social e as novas tecnologias, a enunciação no jornalismo impresso sofreu três modificações no tocante à difusão de informações: 1) leveza dos suportes técnicos; 2) informação no estado bruto (sem edição); 3) desrespeito à gramaticalidade dos manuais de redação, a partir de uma fusão entre a ética e a estética (uma sociologia do efêmero).

O que se faz premente entender, com o auxílio da Sociologia Compreensiva, a partir de Simmel, por exemplo, é a multiplicação das formas geométricas que aumenta as tensões nas cidades. Nas grandes cidades, a garantia simétrica de suas formas financiadas pelo Leviatã vai se perdendo.

Pode se pensa que para enfrentar o medo do Leviatã, às vezes representado pelos partidos políticos no poder, se retorne às formas sociais arcaicas de origem do Poder como os bandos e a tribo, como aconteceu no Brasil pós-eleição 2014, período no qual boa parte dos eleitores quis e rogou a divisão do país em regiões mais cultas e menos cultas politicamente. Na verdade, o que se viu foi alguns querendo manter o Leviatã, outros o refutando, mas todos pensando a partir de uma lógica do pathos social. 


\section{3- As ruas acenam ao Leviatã}

Nos protestos de junho de 2013, o movimento dos corpos recuperou a ideia de uma geometria-cidadã, na qual as pessoas ratificaram suas reivindicações expressas em seus gestos, indumentárias e vozes.

No jornalismo impresso, uma leitura metodológica desses protestos atende a dois níveis analíticos: 1) a Tese - que é o discurso argumentativo-informativo - legado pelo discurso verbal - que tem como principal função demarcar as referências sociais; 2) a Métis, que não é um discurso referencial, mas um discurso reflexivo sobre o movimento dos sujeitos e suas relações espaço-temporais.

Do ponto de vista do jornalismo informativo, as manifestações de rua, estabeleceram uma forma de anunciar a cidade, a partir da caracterização e nomeação sem se preocupar com as particularidades discursivas.

A partir da visão analítica do movimento, as nomeações limitam a polissemia da imagem, marcado no jornalismo impresso pelo discurso verbal da legenda que impõe uma interpretação verticalizada. A lógica da nomeação torna a tese mais importante que o caráter reflexivo.

O discurso jornalístico imobiliza os protestos de rua, como se eles não fossem extensão dos corpos humanos. Nesse sentido, podemos verificar que a iconografia reveladora da luta contra o Leviatã, através das forças sociopolítica, demarca apenas uma ordem discursiva: a fala das instituições.

A outra possibilidade de enxergarmos os protestos, como parte da geometria das cidades (a geometria é imóvel, enquanto a geografia é móvel) é verificar como as metrópoles são corpos (moles) que vão sendo modificadas de acordo com o poder discursivo de cada grupo social na produção de saberes diferenciados: trabalho, ação e conflitos socioeconômicos. A esses saberes chamamos de metis.

Enquanto a tese trata da lógica da nomeação de eventos sociais, das representações institucionais e seus discursos argumentativos, o que podemos definir como sociabilidade; a metis vai tratar das formas geométricas, ou seja, imóveis, que os 


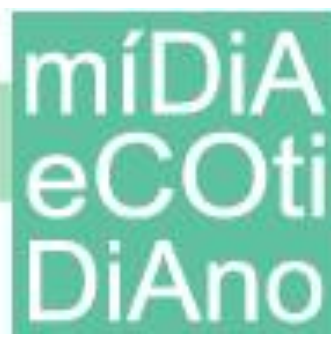

discursos assumem na luta contra o estado regulador, o Leviatã. A isso denominamos de socialidade.

Essa socialidade representa os movimentos geométricos do social, que se apresentam como forças sinestésicas conflituosas em relação à instrumentalização do discurso dos atores sociais. O que induz a pensar que todo discurso verbal ou imagético rico em subjetividade é algo que fere o Leviatã.

\section{1- Capa do Jornal da Paraíba da edição do dia 21 de junho de 2013}

Como forma de analisar os gestos dos manifestantes do junho de 2013 na cidade de João Pessoa, capital do Estado da Paraíba, a partir da pesquisa em curso no Programa de Pós-Graduação em Comunicação da Universidade Federal da Paraíba, escolhemos analisar as fotos publicadas no Jornal da Paraíba, edição de 21 de junho de 2013.

Nesta representação iconográfica, vemos a limitação anunciativa marcada pela nomeação da manchete "Paz e Humor marcam os protestos nas ruas da PB", tais expressões tornam-se conflituosa se analisadas a partir da sociologia do cotidiano de Michel Maffesoli, pois essa sociologia nos apresenta as formas de compreensão da sociedade.

A palavra Paz, da forma como aparece na manchete, tenta explicar que o protesto não foi marcado por conflitos violentos, no entanto, limita a capacidade de entender as várias formas de violência simbólica que delimitam os espaços em um protesto de rua. Uma vez que, a própria palavra "protesto" determina a ideia de conflito social.

Já a palavra humor, em geral, utiliza figuras de linguagem para desestabilizar o status quo. Dessa forma, o enunciado se inscreve na ordem da sociabilidade, ratificando a força do Leviatã contra os movimentos de rua.

Além disso, a polissemia da imagem principal é reduzida pelo discurso verbal da manchete, pois apresenta uma assepsia dos gestos através de uma imagem panorâmica que demonstra apenas o espaço da manifestação. Portanto, esse discurso imagético é da ordem da sociabilidade. 


\section{2- Caderno de Últimas do Jornal da Paraíba da edição do dia 21 de junho de} 2013: a espiral da Metis contra a imobilidade do Leviatã

$\mathrm{Na}$ "geografia" da página do jornal impresso, podemos perceber contradições entre o sistema analógico, as imagens, e o sistema verbal, ora reforçando o caráter institucional dos discursos que anunciam os protestos de rua de junho de 2013, em que predomina a razão do estado; ora, deixando ver os movimentos corporais que induzem o leitor a uma reflexão sobre a sociabilidade (as relações não contratuais em sociedade).

Na mesma página constatamos discursos verbais contraditórios, a manchete marcada pelo caráter aritmético, que é peculiar a sociabilidade, que nomeia o ato a partir do quantitativo: "25 mil pessoas vão às ruas".

Abaixo das imagens principais da página, o editor nomeou a manifestação como um movimento que congrega vários ideais, em que esse discurso se caracteriza como geométrico que é da ordem da socialidade.

\section{CONCLUSÃO}

No século XXI, as cidades se transformaram. Adquiriram novas linguagens, objetivas ou subjetivas que ultrapassam os limites externos e internos. Agora, não há mais como se proteger dos bárbaros através de muralhas, pois é necessário entender as linguagens desses, para que eles não dominem e tome de assalto as linguagens do Estado.

O Leviatã foi inibido pelo poder do grito da sociedade. Os gestos dominaram a opressão que o Estado estava preparado para ter como resposta a uma manifestação organizada. No entanto, a difusão de reinvindicações e a insatisfação social levaram as pessoas às ruas do país. E dessa vez os matizes ideológicos não foram mais importantes que a sensação de estar-junto, no sentido antropológico.

As imagens no jornalismo impresso demonstram que houve uma lacuna interpretativa em relação ao marco reivindicatório dos diversos atores sociais que usaram novas linguagens de enfretamento ao estado. 
A linguagem política, no século XXI, se evidencia no imaginário de cada grupo social capaz de legitimar a fala através dos gestos, das vestimentas e de uma tribalização dos corpos. Por isso, um dos problemas a ser enfrentado pelo pesquisador da linguagem imagética, com relação aos movimentos sociais enunciados no jornalismo impresso, é verificar se os gestos dos manifestantes são reduzidos à imobilidade do discurso verbal, legitimando o discurso do Estado.

\section{REFERÊNCIAS}

AGAMBEN, Giorgio. (2015). Meios sem fim: notas sobre a política. Tradução Davi Pessoa Carneiro. Belo Horizonte: Autêntica Editora.

CAMARGO, I. A. (2000). A construção do objeto noticioso na edição da mídia impressa: fotografia, legenda e texto. Porto Alegre: PUCRS. Disponível em: <http://www.compos.org.br/data/biblioteca_1385.pdf> Acesso em 03 fev 2015.

CHARAUDEAU, P. (2006). Discurso das Mídias. São Paulo: Contexto.

DETINNE, Marcel E VERNANT, Jean Pierre. (2008). Métis - As astúcias da inteligência. São Paulo: Odysseus Editora.

GINZBURG, Carlo. (2008). Medo, reverência, terror - Quatro ensaios de iconografia política. São Paulo: Companhia das letras.

JOLY, M. (1996). Introdução à análise da imagem. Campinas: Papirus.

ZYGMUNT, Bauman. (2009). Confiança e medo na cidade. Rio de Janeiro: Editora Zahar. Edição eletrônica posição $74 \%$.

VASCONCELLOS, M. (2004). Política e mídia: as fotografias dizem tudo! Marília, SP: Universidade de Marília. Disponível em: <http://encipecom.metodista.br/mediawiki/images/d/d8/GT5_-_13_-_Politica_e_Midia_Mercia.pdf> Acesso em 24 jun de 2015 